\title{
LATEX ALLERGY AND SENSITIZATION IN CITIES: A SURVEY IN A POPULATION AT RISK
}

\author{
M.T. VENTURA, M. MUSTI ${ }^{1}$, G. GIULIANO, A. ARSIENI, E. DI LEO, \\ R. BUQUTCCHIO, G. ACCETTURA, A. SPANEVELLO ${ }^{2-3}$, M.P. FOSCHINO-BARBARO ${ }^{3}$ \\ and O. RESTA ${ }^{4}$
}

Department of Internal Medicine, Immunology and Infectious Diseases (MIDIM), University of Bari Medical School, Policlinico, Bari, 'Department of Internal Medicine and Public Medicine, Industrial Medicine, University of Bari; 'Institute of Respiratory Diseases, Fondazione Maugeri, Cassano Murge, Bari; ${ }^{3}$ Institute of Respiratory Diseases, University of Medicine, Foggia; ${ }^{4}$ Institute of Respiratory Diseases, University of Medicine, Bari, Italy

\section{Received March 1, 2006 - Accepted July 13, 2006}

\begin{abstract}
The constant increase in allergic diseases in western countries is correlated with changes in lifestyle and with the deterioration of the air inhaled by the inhabitants because of the growing concentrations of pollutant substances present. Within a population at risk, i.e., the inhabitants of cities, a group of subjects at even higher risk was selected, whose job exposes them to automobile exhaust fumes for many hours a day. All the study subjects underwent allergological sereening and spirometry. The results obtained show an overall increase of respiratory allergic diseases but no increased sensitisation to latex. It therefore seems plausible that, besides social and lifestyle changes, the deterioration of the quality of the air could be considered responsible, at least in part, for the growing numbers of allergic subjects. This study offers an opportunity to reconsider the validity of the "hygiene hypothesis" as an explanation for the increase of allergic disease in western countries, although recent reports have indicated that a sedentary lifestyle may also contribute, together with environmental degradation, to the notably increased prevalence of allergic diseases in large cities in industrialized nations.
\end{abstract}

In western countries, the growth of urban agglomerates has not only caused profound changes in lifestyle, but also a significant degree of environmental degradation (1-4), together with an increased incidence of allergic diseases. The parallel, relatively recent rise in the volume of road traffic seems to be the main cause of the deterioration of the air quality in modern cities. The most abundant atmospheric polluting substances in cities are nitrogen dioxide $\left(\mathrm{NO}_{2}\right)$, ozone $\left(\mathrm{O}_{3}\right)$ and so- called particulates (5). The rubber particles present in the air in our cities, deriving from the friction of tyres on the tarmac, must be added to this list (6-7).

Our study examined a sample of traffic wardens in the city of Bari, who had directed the traffic for at least 3 years, undergoing exposure for many hours daily to automobile exhaust fumes and rubber tyre particles, which could accumulate in the airways and reach the sensitization threshold. In fact, if the inhabitants in urban areas can be said to represent

\section{Key words: asthma, hygiene hypothesis, latex, lifestyle}

Mailing address: M.T. Ventura, M.D.,

Department of Internal Medicine,

Immunology and Infectious Diseases,

University of Bari, Policlinico,

Piazza G. Cesare $n^{\circ} 11,70124$ Bari, ltaly

Tel: +390805592789 Fax: +390805593007

e-mail: mt.ventura@allergy.uniba.it

$0394-6320(2006)$

Copyright 0 by BIOLIFE, s.a.s.

This publication and/or article is for individual use only and may not be firthe 
a population at higher risk of allergic sensitization, then traffic wardens must be considered to be at the top of this hypothetical relative risk scale.

In particular, our aim is to verify whether, in subjects with exposure to atmospheric pollutants for occupational reasons, there is a greater prevalence of respiratory diseases of an irritant or aspecific inflammatory nature, as well as a greater prevalence of allergic respiratory diseases. In addition, we wished to investigate whether aspecific disease is a risk factor for allergic disease and, if so, what allergens are implicated, as well as whether there is any correlation between an increased sensitization to a given pollen and any morphological alterations. Finally, we wished to ascertain whether in such a population there is an increased prevalence of allergies, either respiratory or cutaneous, to rubber latex.

\section{MATERIALS AND METHODS}

This study, conducted in collaboration with the Institute of Occupational Medicine of Bari University Hospital and thanks to the support of the Bari Municipality and Municipal Police Headquarters, was carried out in a sample of traffic wardens (study sample) and a sample of office workers (controls); all the subjects worked for the Municipality. The traffic warden group consisted of 103 subjects, 68 males and 35 females aged between 25 and 58 years (mean age 41.16 years), who had directed traffic for at least 3 years. The control group consisted of 134 subjects, 49 males and 84 females aged between 28 and 64 years (mean age 46.93 years).

After giving informed consent to participate in the study, all subjects completed a questionnaire about personal, residential and occupational (present and past) data, personal and family medical history, the reasons for, and outcome of, any radiological examinations. Other questions probed: any smoking habits; leisure activities; symptoms over the last year suggestive of allergy and/or bronchial obstruction and any reduction of the referred symptoms after a change in the working environment and exacerbation on return to the same environment; occupational or non-occupational contact with rubber articles; any history of previous surgical procedures; the use of condoms; contact with the ficus Benjamin plant.

\section{Skin Prick Test}

A positive control (histamine, $10 \mathrm{mg} /$ ) and a negative control (glycerinated saline) with a standard panel of allergens, Graminacea, Artemisia, Parietaria, Olive,
Cypress, Alternaria, Dermatophagoides pteronyssinus, Dermatophagoides farinae, Dog epithelium, Cat epithelium (Merk-Allergopharma, Reinbek, Germany), as well as rubber latex, using two commercial extracts (Stallergenes, France and Alk-Abello, Madrid, Spain) and the most common foods that cross-react with latex: Banana, Kiwi, Avocado, Tomato, Passion Fruit (MerkAllergopharma), were administered and interpreted in accordance with the European Academy of Allergology and Clinical Immunology (EAACI) Sub-committee on Allergen Standardization and Skin Tests. The response is considered positive if the diameter of the wheal is more than $3 \mathrm{~mm}$ bigger than a wheal provoked by the negative control (8).

\section{Radioallergosorbent Test (RAST)}

To determine specific serum IgE titres for latex, RAST was performed and evaluated according to the manufacturer's instructions, as was the CAP system (Pharmacia, Uppsala, Sweden) (9). The values are calculated as kUA/1. Values are considered as follows: $<0.35 \mathrm{kUA} / 1$ - negative; between 0.35 and 0.7 - low; between 0.7 and 3.5 - moderate; between 3.5 and 17.5 - high; between 17.5 and 50 - very high; $>50$ - extremely high .

\section{Spirometry}

The subjects subsequently underwent pulmonary function tests by spirometry. The forced expiratory volume per second (FEV1) and the forced vital capacity (FVC) were measured using a spirometer (Pony graphic, Cosmed, Italy). The best value of the three manoeuvres was expressed as a percentage of the predicted normal value.

\section{Statistical Analysis}

SPSS Software was used for the statistical analyses. The frequencies have been compared. P-values $\geq 0.05$ were not considered statistically significant.

\section{RESULTS}

\section{Medical History}

There was a highly significant difference between the percentage of traffic wardens $(67.96 \%)$ versus office workers $(54.48 \%)$ who referred a history of symptoms suggestive of allergy. Comparison of the two groups of symptoms, i.e. affecting the bronchi (wheezing, coughing, dyspnea) or the skin (dermatitis, urticaria/angioedema), did not elicit any significant differences, although skin symptoms showed a trend towards a higher frequency in traffic 
wardens. Instead, rhino-conjunctivitis was clearly more frequent in traffic wardens; this difference was statistically significant (Table I).

In $23.30 \%$ of traffic wardens and $11,94 \%$ of office workers, an overall decline of the symptoms was referred during periods of absence from the working environment and a relapse when they returned to work. Again, this difference was statistically significant $(p<0.05)$.

\section{Skin Prick Tests}

Positive results to skin prick tests were obtained in 40 traffic wardens $(38.83 \%$ of the sample) versus 37 office workers (27.61\% of the sample). This difference is almost entirely attributable to aeroallergens, since in only one subject, a traffic warden, positive results were obtained for a food product but not for aeroallergens. Three traffic wardens $(2.91 \%)$ and one office worker $(0.75 \%)$ were positive for foods cross-reacting with latex.

As shown in Table II, there was a statistically significant higher percentage of positive results to Artemisia, Cypress and Dog epithelium and a trend, not statistically significant, towards a higher percentage of positivity to Dermatophagoides pteronyssinus and Dermatophagoides farinae. The percentage of positivity to Olive, Parietaria and Cat epithelium was similar in the two groups. Instead, there was a higher percentage of positivity to Graminacea and Alternaria in the office workers, although this did not reach statistical significance. No positive skin prick test results were obtained to latex, performed with two commercial extracts, either in the traffic wardens or the office workers group. Skin prick tests to some of the more common foods crossreacting with latex were positive in 3 traffic wardens and only 1 office worker. There were no statistically significant differences.

\section{Specific Serum IgE}

Specific serum $\operatorname{IgE}$ for latex were low or moderate as judged by the parameters supplied by the manufacturer (9), being between 0.37 and $1.65 \mathrm{kUA} / 1$ (Table III). Although the mean values of $\operatorname{IgE}$ varied in the two groups, they were within a moderate range in both. The total number of cases with positive IgE for latex was too low for statistical calculations (Table III). Specific IgE were, in fact, found in 3 traffic wardens $(2.91 \%)$ and 4 office workers $(2.98 \%)$. All the seropositive subjects also yielded positive skin tests to aeroallergens but not to latex or cross-reacting foods. Previous surgical procedures (from 1 to 4 ) had been performed in 6 of the 7 subjects. The only subject who had not undergone surgery referred a relatively frequent use of rubber gloves and condoms, albeit without any adverse reaction. Only one of the positive subjects, a control, had concomitant signs and symptoms of thinitis and bronchial obstruction, which correlated with sensitization to Graminacea, Olive and Artemisia pollens.

\section{Spirometry}

The diagnosis is automatically made by the device. Results were within normal limits or showed very mild signs of restriction in $97.08 \%$ of the traffic wardens and $94.03 \%$ of the office workers.

Thus, spirometric alterations were observed in 3 traffic wardens $(2.91 \%)$ and 8 office workers $(5.97 \%)$; analyzing these subgroups, there were no differences as regards mild or moderate obstruction (1.94 and $1.92 \%$, respectively); severe obstruction was observed in 3 office workers (who had already referred that they suffered from bronchial asthma) and none of the traffic wardens; moderate/severe restriction was observed in 4 office workers and only one traffic warden ( 2.98 and $0.97 \%$, respectively). None of the above differences was statistically significant.

\section{Symptoms Among Atopic Traffic Wardens}

Of the 39 traffic wardens with positive SPT to aeroallergens, only 6 had no correlated symptoms, whereas the other 33 suffered from the following complaints: rhinitis and conjunctivitis in 26 subjects $(66 \%)$, urticaria-angioedema in 8 subjects $(20.51 \%)$, pruritus in 5 subjects $(12.82 \%$ ); in addition, 11 subjects (28.21\%) suffered from dyspnea, 3 subjects (7.69\%) from wheezing and 8 subjects (20.51\%) from a dry cough.

\section{DISCUSSION}

The remarkable and parallel increase in allergies and in the urbanization process that has occurred in the last few decades has prompted the hypothesis 
Table I. Symptoms of allergic disease.

\begin{tabular}{|c|c|c|c|c|c|}
\hline \multirow[t]{2}{*}{ SYMPTOMS } & \multicolumn{2}{|c|}{ TRAFFIC WARDENS } & \multicolumn{2}{|c|}{ OFFICE WORKERS } & \\
\hline & Subjects & Percentage & Subjects & Percentage & p values \\
\hline Rhinoconjunctivitis & 48 & 46.60 & 43 & 32.09 & $p<0.05 *$ \\
\hline $\begin{array}{l}\text { Skin (pruritus, dermatitis, } \\
\text { eczema) }\end{array}$ & 25 & 24.27 & 23 & 17.16 & $\mathrm{n} \cdot \mathrm{s}^{*}$ \\
\hline Urticaria-angioedematosis & 15 & 14,56 & 13 & 9.70 & n.s s $^{*}$ \\
\hline $\begin{array}{l}\text { Bronchial (wheeze, cough, } \\
\text { constricted chest, dyspnea) }\end{array}$ & 23 & 22.33 & 31 & 23.1 & $n . \mathrm{s}^{\mathrm{s}}$ \\
\hline TOTAL & 70 & 67.96 & 73 & 54.48 & $\mathrm{p}<0.05^{* * *}$ \\
\hline
\end{tabular}

$*=$ not significant $\quad * *=$ statistically significant

that the two phenomena might be at least partialy correlated.

The dismantling of the Berlin Wall in 1989 offered a unique opportunity to compare, at time zero, two realities featuring comparable geographic and genetic conditions but profoundly different lifestyles and living standards, and to follow the subsequent evolution, i.e. the Westernization of East Germany. While the initial data (10) demonstrated an evidently lower prevalence of allergies in ex East Germany, raising doubts as to the role of severe air pollution of industrial type in triggering an allergic phenotype, the data obtained a few years later (11) contradicted the earlier assumptions. The adoption of the western lifestyle (12), while improving the economic, social, hygiene conditions, etc, also increased the risk of developing allergies, reducing the former differences. Certainly, in the richer and socially more advanced first world, various factors may contribute to the greater incidence and prevalence of allergy. We have only to think of the observations recently summarized in the hygiene hypothesis, which explain the development of Th2-like lymphocytic clones (13-16). However, there was another important aspect underlying the change for East Germans: the composition of the air, in which the classic industrial pollutants had declined, whereas the automobile exhaust fumes had increased to levels similar to those in the rich Western cities (11). There is well-documented evidence that within the same geo-ethnic group, allergic diseases are more common among those who live in urban areas and, still more significantly, among those who live near main roads with heavy traffic, even in cases of similar or lesser concentrations of allergizing pollens (17-24).

However, in a recent study carried out by Ventura et al. (25) on a population of Albanian immigrants to Southern Italy, we found an increasing prevalence of allergic sensitization to local allergens after immigration. In particular, the increased sensitization to common inhalants was correlated to the length of their residence in Apulia. Antibodies against Hepatitis A virus, Herpes simplex virus 1 , Helicobacter pylori and Toxoplasma gondii were found in the sera of these subjects. These data support the hypothesis that a higher exposure to infections could have a protective effect against the development of allergic diseases (the hygiene hypothesis) (16). In addition, the Authors (25) suggest that exposure to allergens, together with lifestyle factors, can influence the onset and course of allergic diseases.

Moreover, the fact that in this population the incidence of inhalant sensitization rose to levels typical of Southern Italy stresses the responsibility of environmental factors, and in particular of air pollution, in the onset of new forms of sensitization and allergic symptoms even in populations with a previously low prevalence of allergy. In this context, in immigrants from South-East Asia, Leung found an association with an increase in allergic diseases 
Table II. Results of skin prick tests.

\begin{tabular}{|c|c|c|c|c|c|}
\hline \multirow[t]{2}{*}{ Allergens } & \multicolumn{2}{|c|}{ TRAFFIC WARDENS } & \multicolumn{2}{|c|}{ OFFICE WORKERS } & \multirow[b]{2}{*}{ P Values } \\
\hline & Positive & $\begin{array}{c}\text { Subjects } \\
\%\end{array}$ & Positive & $\begin{array}{c}\text { Subjects } \\
\%\end{array}$ & \\
\hline Graminacea & 12 & 11.65 & 21 & 15.67 & n.s.* \\
\hline Artemisia & 10 & 9.70 & 6 & 4.48 & $p<0.05^{* *} *$ \\
\hline Parietaria & 9 & 8.74 & 11 & 21 & n.s.* \\
\hline Olive & 16 & 15.53 & 19 & 18 & n.s. $*$ \\
\hline Cypress & 18 & 17.48 & 11 & 8.21 & $p<0.05 * *$ \\
\hline $\begin{array}{l}\text { Dermatophagoides } \\
\text { pteronyssinus }\end{array}$ & 18 & 17.48 & 18 & 13.43 & n.s.* \\
\hline $\begin{array}{l}\text { Dermatophagoides } \\
\text { farinae }\end{array}$ & 16 & 15.53 & 15 & 11.19 & n.s.* \\
\hline Alternaria & 0 & 0 & 2 & 1.49 & n.s.* \\
\hline Dog & 11 & 10.68 & 6 & 4.48 & $\mathrm{p}<0.05 * *$ \\
\hline Cat & 6 & 5.82 & 7 & 5.22 & n.s.* \\
\hline Latex & 0 & 0 & 0 & 0 & \\
\hline Banana & 1 & 0.97 & 1 & 0.78 & n.s. ${ }^{*}$ \\
\hline Kiwi & 1 & 0.97 & 1 & 0.78 & n.s.* \\
\hline Avocado & 2 & 1.94 & 0 & 0 & n.s.* \\
\hline Passion fruit & 0 & 0 & 0 & 0 & $n . s^{*}$ \\
\hline Tomato & 1 & 0.97 & 0 & 0 & n.s.* \\
\hline
\end{tabular}

$*=$ not significant $\quad * *=$ statistically significant

and asthma after their arrival in Australia, due to environmental factors and correlated with the duration of their residence in Australia (26).

In addition, evidence for an effect of environmental agents on immune conditions has been stressed by Powell et al. (27). In particular, following xenobiotic exposure, individuals can react differently to chemicals (including ultraviolet radiation, ozone etc.), developing important changes with a strong implication on human health.

As to the possible role of the single pollutant substances, a leading role is certainly played by the so-called respirable particulates, the main source of which is diesel engines (these particulates are therefore named DEPs). These DEPs can act both on allergens, by adsorbing them (28-31) and concentrating them, and by carrying them into even the smallest calibre airways, thus up-regulating the inflammatory response (31-35). In fact, thanks to their liposoluble hydrocarbon component they can damage the ciliary apparatus of the upper airways (36-37), reducing their clearance powers 
Table III. Specific Ig E for latex.

\begin{tabular}{|c|c|c|c|}
\hline \multicolumn{2}{|c|}{ Traffic Wardens } & \multicolumn{2}{c|}{ Office Workers } \\
\hline Cases & IgE concentration & Cases & IgE concentration \\
\hline 1 & $0.37 \mathrm{kUA} / 1$ & 1 & $0.39 \mathrm{kUA} / 1$ \\
\hline 2 & $0.96 \mathrm{kUA} / 1$ & 2 & $0.65 \mathrm{kUA} / 1$ \\
\hline 3 & $1.65 \mathrm{kUA} / \mathrm{l}$ & 3 & $0.70 \mathrm{kUA} / 1$ \\
\hline & & 4 & $1.55 \mathrm{kUA} / 1$ \\
\hline & & & \\
\hline
\end{tabular}
(Mean value 0.99) (Mean Value 0.82)

and therefore causing a longer persistence in loco of the pollutant substances. Moreover, because they are liposoluble, they can easily penetrate the respiratory epithelial barrier and enter the epithelial and endothelial cells, macrophages and lymphocytes where, by inducing oxidative stress, they activate some transcription factors such as NFkB, AP-1 and AP-2. These then bind to the promoter regions of the genes coding for ICAM-1, VCAM-1, IL-6, IL-8 and GM-CSF and for the histamine receptor (38-39). By means of other mechanisms, they probably also induce the synthesis of IL-4, IL-5, IL-13, IL-10.

Thus, it is possible that a genetically predisposed subject living in a modern Western city, when coming in contact with allergens that have been made more "aggressive" by binding to the polyaromatic hydrocarbons contained in the fine DEPs, is primed by this inhalation of the pollutants to produce Th2-like cytokines (and consequently IgE). These chemotactic cytokines for various cell types and adhesion molecules serve to recruit and store these cells in the respiratory inflammation sites and, finally, the subject is stimulated to produce histamine receptors, up-regulating the clinical response to the allergen and enhancing the effects of the cascade of IgE-mediated reactions.

The allergological significance of rubber latex has been known for the last 20 years, and its presence as a solid pollutant in the urban air, due to tyre friction against the tarmac, has long been demonstrated (6-7). Besides the classic risk categories, namely health workers, pluri-operated patients and industrial workers, there may now be a new category: the inhabitants of cities with dense traffic. The few data available in literature on this subject are contradictory.
A pilot study conducted in Switzerland (40) in a population of adolescents demonstrated a positive correlation between exposure to road traffic and latex sensitization. Instead, in a survey in a large German population (41) of more than 2,500 children from Dresden, assessing the presence of specific $\operatorname{IgE}$ for latex and correlating them with exposure to traffic exhaust fumes, the opposite conclusions were drawn.

In our study we found a statistically significant increased sensitization to the allergens of Cypress, Artemisia and Dog epithelium and, to a lesser extent, of house dust mites. There was also a statistically significant higher prevalence of rhinitisconjunctivitis symptoms. Instead, there was no significant difference between the two groups as regards pharyngo-tracheo-bronchial symptoms, nor spirometric signs of bronchial obstruction. Neither was there any evidence that the urban environment can foster a greater sensitization to rubber latex or additives used in the rubber processing cycle.

A combination of various circumstances could justify our findings of a higher percentage of sensitization to only a few allergens. Certainly, working activities conducted in the open air are in themselves risk factors for sensitization to environmental allergens. However, we did not observe a greater prevalence of skin positivity to Graminacea, Parietaria and Olive pollens, which are the most common in our geographic area (indeed, sensitization to Graminacea was found to be more common in the control group). However, it is possible that these pollens, which have a stronger allergenic power than those of Cypress and Artemisia, may have "exhausted" their ability to increase the exposure-related sensitization rate. In other words, 
they may have reached a plateal, whereby the factor limiting the development of the allergic phenotype might no longer depend on exposure, but only on the genetic make-up of the individual or on other, different environmental factors. Instead, Cypress and Artemisia pollens might be more dependent on exposure, due to their lesser intrinsic allergenicity (cypress) or lower concentration in the atmosphere (Artemisia), both circumstances which would entail a longer exposure to induce sensitization. In any case, it should be borne in mind that in the city of Bari, the daily cypress pollen count is extremely variable and reaches a fairly modest annual total, as reported by some Authors (42). The same considerations apply to dog epithelium allergens.

A clearly higher rate of sensitization to Cypress pollens was reported in the historic study by Ishizaki (17) on Criptomeria japonica or Japanese cedar, an essence with an affinity to cypress despite its different taxonomy, whose pollens were demonstrated to be more aggressive in urban than in rural areas, regardless of the degree of exposure. Although the subjects in our study were more exposed to cypress pollens, this did not apply to the inhabitants of Nikko in Ishizaki's study (17). Cypress and Japanese cedar pollens might undergo similar morphological alterations due to interaction with atmospheric particulates deriving from exhaust fumes, making their allergens more readily available. Cross-reactivity between the main allergens of these two conifers has been demonstrated, as well as an analogous structure and the presence in Cry $\mathrm{j} I$ of a glycosylate residue (43). A study conducted by the University of Bari in collaboration with the Ministry of Health (44) demonstrated glycosylation of the allergenic components of Cupressus arizonica pollen extracts, thanks to their ability to bind various lectins. This is another finding suggesting that Lol $\mathrm{p} 1$, a glycosylated protein, binds DEPs, whereas Lol p5 (non glycosylated) does not, and that the allergens of Cypress and Japanese cedar may build similar relations with the organic component of the DEPs (29). Moreover, subjects contracting a cold may be predisposed to sensitization to cypress, and the peak winter season for colds coincides with the pollen period of Cypress, virtually the only plant pollinating in this season to be listed among the main allergenic essences.
Apart from a possible increased presence of dog epithelium allergens in the urban environment, which might sensitize more exposed subjects, it has been demonstrated, at least in vitro, that DEPs bind the main dog allergens, as well as dust mite allergens (which are also glycosylated) (28). This could further justify a greater sensitization power in subjects exposed to road traffic. It is also plausible that, as well as acting as a vector carrying these allergens from the air to the airways, DEPs may capture them in the air in confined environments, acting from the surface of the rhino-bronchial epithelium where they may lodge. In other words, it cannot be excluded that binding between DEPs and allergens, inhaled at different times, may also occur within the airways. This sequence could be particularly active in the case of dust mite allergens: after a working day in the traffic, the respiratory epithelium could be full of aromatic hydrocarbons derived from DEPs, and during the night they could come in contact with dust mite allergens and bind with them.

As to the clinical and spirometric data, it should be stressed that there was a higher incidence of seasonal rhinitis-conjunctivitis symptoms among the traffic wardens, which is more directly correlated with increased allergic sensitization, especially to Cypress. On the contrary, there were no statistically significant differences as regards pharyngo-laryngobronchial symptoms between the two groups, and indeed the spirometric examinations showed more frequent alterations, of both obstructive and restrictive type, among the office workers than among the traffic wardens. While this finding excludes a contribution of aspecific respiratory disease to inducing sensitization to aeroallergens, it stresses once more the effects on health of indoor pollution (cigarette smoke, allergens, microorganisms, etc.), and perhaps also of a sedentary lifestyle.

This concept has recently been underlined by Plats-Mills et al. (45). The authors suggest that changes in the "western" lifestyle are correlated to an increased prevalence of asthma. The "western" lifestyle features reduced physical activity and an increased rate of obesity. In addition, the "hygiene hypothesis" proposes that some elements, such as lack of exposure to endotoxins and helminth infections or contact with farm animals, may cause an increase in lymphokines capable of defending 
the organism against bacterial and viral noxae. This lymphokine imbalance could predispose to the production of lymphokines deputed to respond to allergic stimuli, justifying the increasing prevalence of allergy and asthma in urban environments (46).

Our negative results to skin prick tests to latex in all subjects and the low or very low titres of specific IgE - virtually identical in both groups, found only in atopic subjects and in any case with no clinical correlations - confirm the data in literature and indicate that traffic wardens are comparable to the general population in this context. However, 6 of the 7 subjects with specific IgE for latex had undergone between 1 and 4 surgical procedures, confirming this type of exposure as an important risk factor for sensitization, probably not only due to repeated exposure but also to the high allergenic concentrations present in the health care environment.

The immunologically active concentration of latex proteins present in the air is extremely low even in dense traffic areas, and largely below the thresholds triggering symptoms in sensitized subjects, or inducing sensitization in previously negative subjects (47-48). Continual exposure to low concentrations of latex, in combination with other substances with an inducing, and maybe a vector action, could give rise to accumulation phenomena and ultimately induce sensitization. However, the data emerging from the present study do not support this hypothesis, and are in agreement with Hirsch's results showing no relation between exposure to traffic and rubber latex allergy (41).

In conclusion, we do not know for certain why in recent years allergic disease has been constantly on the increase. However, we do know that this phenomenon must depend largely on environmental factors, which probably have a different weight in different individuals. In some people, many vaccinations could play a role; in others, the fact of growing up in a small family and hence contracting few infectious diseases; in yet others, an excessive use of antibiotics or a diet consisting of well preserved but sterile foods. Other possibly implicated factors include excessive exposure to allergens or exposure to a new, previously unknown one. Finally, for some people the decisive factor may well be living in a city and breathing in the pollutants deriving from"progress".

\section{ACKNOWLEDGEMENTS}

We thank Bari Municipality and Municipal Police Headquarters for their cooperation.

\section{REFERENCES}

1. European Community Respiratory Health Survey. 1996. Variations in the prevalence of respiratory symptoms, self-reported asthma attacks and the use of asthma medication in the European Community Respiratory Health Survey (ECRHS). Eur. Resp. J. 9:687.

2. The International Study of Asthma and Allergies in Childhood (ISAAC) Steering Committee. 1998. Worldwide variation in prevalence of symptoms of asthma, allergic rhinoconjunctivitis and atopic eczema: ISAAC. Lancet 351:1225.

3. European Allergy White paper. 1997. Allergic disease as a public health problem. UCB Institute of Allergy, Braine-1'Alleud (Belgium).

4. Renzoni E., F. Forestiere, A. Biggeri, G. Viegi, L. Bisanti, E. Chellini, G. Ciccone, G. Corbo, C. Galassi, F. Rusconi and P. Sestini. 1999. Differences in parental- and self-report of asthma, thinitis and eczema among Italian adolescents. SIDRIA collaborative group. Studi Italiani sui Disordini Respiratori dell' Infanzia e l'Ambiente. Eur. Respir. J. 14:597.

5. Parnia S., J.L. Brown and A.J. Frew. 2002. The role of pollutants in allergic sensitization and the development of asthma. Allergy 57:11/1.

6. Williams P.B., M.P. Buhr, R.W. Weber, M.A. Volz, J.W. Koepke and J.C. Selner. 1995. Latex allergen in respirable particulate air pollution. J. Allergy Clin. Immunol. 95:88.

7. Miguel A.G., G.R. Cass, J. Weiss and M.M. Glowsky. 1996. Latex allergens in tire dust and airborne particles. Environ. Health Perspect. 104: 1180.

8. European Academy of Allergology and Clinical Immunology. 1989. Skin tests used in type I allergy testing. Position paper. Allergy 44:1.

9. Paganelli R., I.J. Ansotegui, J. Sastre, C.E. Lange, 
M.H. Roovers, H. de Groot, N.B. Lindholm and P.W. Ewan. 1998. Specific IgE antibodies in the diagnosis of atopic disease. Clinical evaluation of a new in vitro test system, Uni-CAP, in six European allergy clinics. Allergy 53:763.

10. von Mutius E., C. Fritzsch, S.K. Weiland, G. Roell and H. Magnussen. 1992. Prevalence of asthma and allergic disorders among children in united Germany: a descriptive comparison. Br Med. J. 305:1395.

11. von Mutius E., S.K. Weiland, C. Fritzsch, H. Duhne and U. Keil. 1998. Increasing prevalence of hay fever and atopy among children in Liepzig, East Germany. Lancet 351:862.

12. Wichmann H.E. 1996. Possible explanation for the different trend of asthma and allergy in East and West Germany. Clin. Exp. Allergy 26:621.

13. Strachan D.P. 1995. Epidemiology of hay fever; toward a community diagnosis. Clin. Exp. Allergy $75: 296$.

14. Shaheen S.O., P. Aaby, A.J. Hall, D.J. Barker, C.B. Heyes, A.W. Shiell and A. Goudiaby. 1996. Measles and atopy in Guinea-Bissau. Lancet 347:1792.

15. Matricardi P.M., F. Rosmini, L. Ferrigno, R. Nisini, M. Rapicetta, P. Chionne, T. Stroffolini, P. Pasquini and R. D'Amelio. 1997. Cross sectional retrospective study of prevalence of atopy among Italian military students with antibodies against hepatitis A virus. BMJ 314:999.

16. Strachan D.P. 2000 . Family size infection and atopy: the first decade of the "hygiene hypothesis". Thorax $55: 2$.

17. Ishizaki T., K. Koizumi, R. Ikemori, Y. Ishiyama and E. Kushibiki. 1987. Studies of prevalence of Japanese cedar pollinosis among residents in a densely cultivated area. Ann. Allergy 58:265.

18. D'Amato G. 2000. Urban air pollution and plantderived respiratory allergy. Clin. Exp. Allergy 30 : 228 .

19. Kramer U., T. Koch, U. Ranft, J. Ring and H. Behrendt. 2000. Traffic-related air pollution is associated with atopy in children living in urban areas. Epidemiology 11:64.

20. Popp W., H. Zwick, K. Steyrer, H. Rauscher and T. Wanke. 1989. Sensitization to aeroallergens depends on environmental factors. Allergy 44:572.
21. Wyler C., C. Braun-Fahrlander, N. Kunzli, C. Schindler, U. Ackermann-Liebrich, A.P. Perruchoud, P. Leuenberger and B. Wuthrich. 2000. Exposure to motor vehicle traffic and allergic sensitization. The Swiss Study on Air Polletion and Lung Diseases in Adults (SAPALDIA) Team. Epidemiology 11:450.

22. Yemaneberhan H., Z. Bekele, A. Venn, S. Lewis, E. Parry and J. Britton. 1997. Prevalence of wheeze and asthma and relation to atopy in urban and rural Ethiopia. Lancet 350:85.

23. Gergen P.J., P.C. Turkeltaub and M.G. Kovar. 1987. The prevalence of allergic skin test reactivity to eight common aeroallergens in the U.S. population: results from the second National Health and Nutrition Examination Survey. J. Allergy Clin. Immunol. 80:669.

24. Braback L. and L. Kalvesten. 1992. Urban living as a risk factor for atopic sensitization in Swedish school children. Pediatr. Allergy Immunol. 2:14.

25. Ventura M.T., G. Munno, F. Giannoccaro, F. Accettura, M. Chironna, R. Lama, M. Hoxha, V. Panetta, L. Ferrigno, F. Rosmini, P.M. Matricardi, S. Barbuti, A. Priftanji, S. Bonini and A. Tursi. 2004. Allergy, asthma and markers of infections among Albanian migrants to Southern Italy. Allergy 59:632.

26. Leung R. 1996. Asthma and migration. Respirology I:123.

27. Powell J.J., J. Van de Water and M.E. Gershwin. 1999. Evidence for the role of environmental agents in the initiation or progression of autoimmune conditions. Environ. Health Perspect. 107:667.

28. Kainka-Stanicke E., H. Behrendt, K. Friedrichs and R. Tomingas. 1998. Morphological alteration of pollen and spores induced by airborne pollutants: observations from two different polluted areas in West Germany. Allergy 43:57.

29. Ormstad H., B.V. Johansen and P.I. Gaarder. 1998. Airborne house dust particles and diesel exhaust particles as allergen carriers. Clin. Exp. Allergy 28:702.

30. Behrendt H., W.M. Becker, C. Fritzsche, W. SliwaTomczok, J. Tomczok and K.H. Friedrichs. 1997. Air pollution and Allergy: experimental studies on 
modulation of allergenic release from pollen by air pollutants. Int. Arch. Allergy Immunol. 113:69.

31. Knox R.B., C. Suphioglu, P. Taylor; R. Desai, H.C. Watson, J.L. Peng and L.A. Bursill. 1997. Major grass pollen allergen Lol $\mathrm{p} 1$ binds to diesel exhaust particles: implications of asthma and air pollution. Clin. Exp. Allergy 27:246.

32. Steeremberg P.A., J.A.J. Zonnenberg, J.A. Dormans, P.N. Joon, I.M. Wouters, L. van Bree, P.T. Scheepers and H. Van Loveren. 1998. Diesel exhaust particles induced release of IL- 6 and IL- 8 by (primed) human bronchial epithelial cells (BEAS2B) in vitro. Exp. Lung. Res. 24:85.

33. Bayram H., J.L. Devalia, R.J. Sapsford, T. Ohtoshi, Y. Miyabara, M. Sagai and R.J. Davies. 1998. The effects of diesel exhaust particles on cell function and release of inflammatory mediators from human bronchial epithelial cells in vitro. Am. $J$. Respir. Cell. Mol. Biol. 18:441.

34. Diaz-Sanchez D., A. Tsien, J. Fleming and A. Saxon. 1997. Combined diesel exhaust particles and ragweed allergen challenge markedly enhances human in vivo nasal ragweed specific $\mathrm{IgE}$ and skews cytokine production to a Th2 type phenotype. $J$. Immunol. I58:2406.

35. Diaz-Sanchez D. 1997. The role of diesel exhaust particles and their associated polyaromatic hydrocarbons in the induction of allergic airway disease. Allergy 52:52.

36. D'Amato G. and G. Liccardi. 2002. The increasing trend of seasonal respiratory allergy in urban areas. Allergy 57:35.

37. Nel A.E., D. Diaz-Sanchez and N. Li. 2001. The role of particulate pollutants in pulmonary inflammation and asthma: cvidence for the involvement of organic chemicals and oxidative stress. Curf Opin. Pulm. Med. 7:20.

38. Salvi S.S., A. Frew and S. Holgate. 1999. Is diesel exhaust a cause of increasing allergies? Clin. Exp. Allergy 29:4.

39. Brown J.L. and A.J. Frew. 2002. Diesel exhaust particles and respiratory allergy. Eur. Respir. Mon. 21:180.

40. Braun-Fahrlănder C., L. Grize, M. Gassner, U.
Neu, F. Sennhauser, H.S. Varonier, J.C. Vuille and B. Wuthrich. 1998. Traffic exposure and sensitization. to latex and pollen. A pilot study (abstract). Epidemiology 9(S):704.

41. Hirsch T., V. Neumeister, S.K. Weiland, E. von Mutius, D. Hirsch, H. Grafe, H. Duhme and W. Leupold. 2000. Traffic exposure and allergic sensitization against latex in children. J. Allergy Clin. Immunol 106:573.

42. Caiaffa M.F., L. Macchia, S. Strada, G. Bariletto, F. Scarpelli and A. Tursi. 1993. Airborne Cupressaceae pollen in Southern Italy. Ann. Allergy $71: 45$.

43. Taniai M., T. Kayano, R. Takakura, S. Yamamoto, M. Usui, S. Ando, M. Kurimoto, R. Panzani and T. Matuhasi. 1993. Epitopes on Cry j I and Cry j II for the human IgE antibodies cross-reactive between Cupressus sempervirens and Cryptomeria japonica pollen. Mol. Immunol. 30:183.

44. Di Felice G., M.F. Caiaffa, G. Bariletto, C. Afferni, R. Di Paola, A. Mari, S. Palumbo, R. Tinghino, F. Sallusto, A. Tursi and L. Macchia, 1994, Allergens of Arizona cypress (Cupressus arizonica) pollen: Characterization of the pollen extract and identification of the allergenic components. $J$. Allergy Clin. Immunol. 94:547.

45. Platts-Mills T.A., E. Erwin, P. Heymann and J. Woodfolk. 2005. Is the hygiene hypothesis still a viable explanation for the increased prevalence of asthma? Allergy 60(S):25.

46. Braun-Fahrlander C., J . Riedler, U. Herz, W. Eder, M. Waser, L. Grize, S. Maisch, D. Carr, F. Gerlach, A. Bufe, R.P. Lauener, R. Schierl, H. Renz, D. Nowak and E. von Mutius; Allergy and Endotoxin Study Team. 2002. Environmental exposure to endotoxin and its relation to asthma in school-age children. N. Engl. J. Med. 347:869.

47. Finley B.L., D.R. Ownby and S.M. Hays. 2003. Airborne tire particles in the environment: a possible asthma risk from latex proteins? Human and Ecological Risk Assessment 9:1505.

48. Baur X., Z. Chen and V. Liebers. 1998. Exposureresponse relationships of occupational infralative allergens. Clin. Exp. Allergy 28:537. 